\title{
Borges: Una Teoría de la Literatura Fantástica
}

En un artículo publicado tres años antes de aparecer su primer libro de ficciones (Historia universal de la infamia, 1935), Borges habrá de encarar el problema básico de la literatura fantástica. Titulado, "El arte narrativo y la magia", el artículo se publica en Sur (no. 5,1932 ) y es recogido el mismo año en un volumen de ensayos, Discusión. ${ }^{1}$ La suerte del artículo ha sido muy curiosa: soslayado por casi toda la critica borgiana, ${ }^{2}$ no será leído como el texto básico que es hasta que los estructuralistas franceses lo descubran, lo traduzcan y lo glosen. Ellos mismos no hacen sino considerar algunos aspectos. Es muy probable que el profesor Angel Flores no lo haya visto antes de escribir su ponencia de 1954 en que trata de presentar (infructuosamente, me temo) a Borges como el punto de partida de un movimiento de "realismo mágico"' en las letras hispanoamericanas que sólo existe en la indocumentada imaginación del profesor Flores. ${ }^{3}$ En realidad, ese artículo ya en 1932 echa por tierra todo intento de asimilar el concepto de literatura fantástica que tiene Borges con cualquier suerte de "realismo", sea mágico o misterioso, maravilloso o místico. Su ensayo es un ataque a fondo del realismo.

Un repaso del mismo puede ser útil. Borges empieza por establecer una afirmación general, casi el arranque de una investigación sobre la poética de la narrativa:

1 Cf. Discusion (Buenos Aires: Gleizer, 1932), pp. 109-124. Las citas se harán por esta edición.

2 Cf. Ana Maria Barrenechea: La expresión de la irrealidad en la obra de Jorge Luis Borges (México, El Colegio de México, 1957), $189 \mathrm{pp}$. Aunque se refiere a "El arte narrativo y la magia", en tres ocasiones (pp. 26, 47-48, 109), en ninguna de ellas analiza Barrenechea dicho texto desde el punto de vista de una poética de la narración. En mi trabajo, "Borges: Teoría y práctica”, en Nümero, No. 27, (Montevideo, diciembre 1955), pp. 124-157, hay un breve resumen de las teorias narrativas de Borges. Ver especialmente las pp. 141-143, en que se analizan pasajes de "El arte narrativo y la magia". Este trabajo tiene como base una conferencia de 1954.

3 En un trabajo titulado, "Magical Realism in Spanish American Fiction", en Hispania, vol. XXXVIII, No. 2 (Baltimore, Madison, May 1955), pp. 187-192, el profesor Angel Flores trata de presentar a Borges como el representante máximo del "realismo mágico". En la ponencia que presenté en el Congreso de Literatura Iberoamericana, en East Lansing, 1973, discuto en detalle el intento del profesor Flores. Ver la Memoria de dicho Congreso, pp. 25-37. Aquí sólo me referiré a lo que tiene que ver con las teorias de Borges. 
El análisis de los procedimientos de la novela ha conocido escasa publicidad. Esa continuada reserva tiene por causa histórica la anterioridad de otros géneros y por causa fundamental la inextricable y morosa conjugación de los artificios novelescos, que es laborioso desprender de la trama. El analista de una pieza forense o de una elegia, posee un vocabulario especial y la oportunidad de exhibir párrafos que se bastan; el de una populosa novela carece de términos convenidos y no puede ilustrar lo que afirma con ejemplos inmediatamente fehacientes. Demando, en vista de eso, un quantum adicional de resignación para las verificaciones que siguen. (p. 109)

Me interesa subrayar, ante todo, esta circunstancia: Borges escribe en 1932. De ahí que su afirmación de base-la de que no se ha dado bastante publicidad al análisis de los procedimientos narrativos-tenga un alcance cronológico muy preciso. En esa fecha había pocas "poéticas" de la narración. Una de las más notorias excepciones: The Craft of Fiction, por Percy Lubbock, amigo y admirador de Henry James, está fechada en 1925. Aunque es cierto que ya había mucho material primario, desde Cervantes y Fielding hasta las espesas teorizaciones de Zola y sus correligionarios. Hoy casi no hay otra cosa que "poéticas", narrativas. El artículo de Borges debe ser situado, pues, en el contexto de su tiempo. Aclarado esto, veamos qué tiene que decir él en particular sobre el tópico central: el arte narrativo y la magia.

Nótese, en primer lugar, que Borges habla de " procedimientos", habla de " artificios novelescos", habla de "trama"'. " Es evidente que su "poética" prefiere partir ya-lo indica el vocabulario-de una concepción del arte narrativo como artificio. También es evidente que a Borges le interesa elucidar ese artificio desde un doble punto de vista: el de los " procedimientos" y el de la "trama". Hay aquí como el esbozo de una disertación a la manera de la Poética, de Aristóteles. Es claro que Borges no es un pedagogo, sino un "poeta". De manera que su análisis no procederá por definiciones y categorías, sino por intuiciones y ejemplos. Ya en la última frase del párrafo inicial se indica el tono: "Demando, en vista de eso, un quantum adicional de resignación para las verificaciones que siguen", Subrayo la palabra "verificaciones". Como la crítica de T.S. Eliot sobre el drama en verso (que ocupa buena parte de los Selected Essays, y a la que tanto se parece ésta de Borges), las "verificaciones" a que se entregará el autor argentino en éste y otros trabajos posteriores tienen el mismo propósito. Son crítica de "practicantes", como dijo el mismo Eliot, crítica cuya finalidad es aclarar al autor, y a su futuro lector, la obra que ya está en preparación. Crítica que abre camino, que anuncia, que prepara el terreno.

En este sentido, Borges habrá de contribuir con este artículo a preparar la recepción de

4 En sus trabajos, Borges habla indistintamente de argumento o de trama. Se refiere siempre, no al tema (fábula, en la definición de los formalistas) sino al desarrollo específico de la acción, al encadenamiento de las partes de la intriga, a la causalidad de la ficción (lo que los formalistas llamaron sujet). La palabra trama es, en este sentido, más explícita que argumento, ya que ésta se suele confundir coloquialmente con asunto o tema. Pero si se va al origen de la palabra argumento (en el sentido de argumentación que tiene en el discurso), se comprende su valor retórico. Borges nunca olvida la retórica. Una observación complementaria : en su artículo sobre Henry James, en Le livre à venir (Paris, Gallimard, 1959, pp. 156-159), Maurice Blanchot lee mal a Borges, y cree que cuando éste habla de "sujets", se refiere a temas, y no a argumentos, o tramas. Tal vez la traducción francesa del texto de Borges lo condujo al error. 
las ficciones que ya en 1933 empieza a publicar en el periódico Critica, de Buenos Aires, y que en 1935 recoge en Historia universal de la infamia. Por eso, en vez de fundar con este artículo una "poética de la narración", funda (echa las bases) de una "poética" de su futura ficción. El método que emplea es el de las muestras. Elige dos textos (anglosajones, los dos) y a partir del examen de algunos de sus procedimientos llega a postular lo que (para él) es uno de los procedimientos básicos del arte narrativo. Es un método empírico y, si se quiere, arbitrario. Podría preguntarse: ¿Por qué elige The Life and Death of Jason, oscurísima novela en verso del artista y escritor pre-rafaelista William Morris? (Es de 1867.)¿Por qué elige la Narrative of $A$. Gordon Pym, la única novela que escribió el cuentista, poeta y ensayista Edgar Allan Poe? ¿Por qué no tomó La guerra y la paz, o Madame Bovary, o The Ambassadors, esas grandes máquinas narrativas del siglo XIX?

¿O Finnegans Wake, A la recherche du temps perdu, Der Prozess? Es evidente que en la elección de sus dos ejemplos, Borges procede con toda deliberación. Ante todo, porque son obras poco transitadas por la crítica internacional, y una de ellas es, sin duda, casi totalmente desconocida fuera del círculo de especialistas.

La supuesta arbitrariedad que hace tiempo estamos acostumbrados a asociar a la crítica de Borges parece funcionar aquí. Es posible.Pero también es posible que esté funcionando ya otro mecanismo, más importante y significativo. Al prescindir tanto de las grandes máquinas novelescas del siglo XIX, como de las experimentales del siglo XX, y preferir obras que cualquier crítico habría considerado laterales, Borges está tomando partido por un cierto tipo de la narración: precisamente aquella que no es lo que se suele llamar una novela representativa. Tanto la obra de Morris como la de Poe presentan aventuras extraordinarias: una vuelve a contar la mítica historia de Jasón y del véllocino de oro; la otra, un viaje imaginario a las desoladas tierras blancas del Círculo Antártico. En las dos obras hay un elemento común: el rechazo tácito de la "poética" del realismo. La obra de Poe antecede al movimiento que con ese nombre fabricaron arduamente en Francia algunos escritores positivistas; la segunda es coetánea de esos esforzados si que distraídos estetas pero no ha sido (felizmente) contaminada por ellos. La elección de Borges, pues, define nitidamente el campo de su análisis y de sus "verificaciones". Lo que a él le interesa en esta "poética"' de la narración es situar una forma narrativa que no tiene nada que ver con el realismo. Por omisión, el realismo queda totalmente excluído de su "poética". O aparecerá sólo como el término que por su ausencia permite definir mejor los que sí están presentes.

En su lectura del libro de Morris, Borges empieza por descartar "cualquier estudio, o apariencia de estudio, de la filiación helénica del poema". Su argumento: "Mi fin es literario, no histórico"'. De ahí que se concentre en lo que para él es lo central en el "proyecto"' de Morris. Según Borges, aquél se propuso

la relación auténtica de las aventuras apócrifas de Jasón, rey de Iolcos. La sorpresa lineal, recurso general de la lírica, no era posible en esa narración de más de diez mil versos. Esta necesitaba ante todo una fuerte apariencia de veracidad, si no absoluta, capaz a lo menos de producir esa espontánea suspensión de la duda, que determina para Coleridge la fe poética. Morris consigue despertar esa fe; quiero investigar cómo. (p. 110) 
Desde ya se advierte cuál es el problema narrativo que Borges se propone elucidar en el caso de Morris: es el problema de la verosimilitud. O como él dice: de "una fuerte apariencia de veracidad'. Pero en vez de examinar el problema a partir de $L$ 'Assommoir, An American Tragedy, La maestra normal-esos azarosos monumentos del realismo naturalista-, Borges elige precisamente una novela, en verso y que es la transcripción victoriana de un mito griego. Es decir: elige una narración no realista. La mención de Coleridge y de su famosa observación-toda lectura, según él, supone "the willing suspension of disbelief' - , ayuda a situar el análisis de Borges en el único campo posible para toda crítica de la narración: el campo del artificio, de las convenciones "poéticas", del arte (en el sentido etimológico de esta palabra). A continuación, Borges analiza los procedimientos por medio de los cuales Morris logra "la difícil verosimilitud" en su presentación de seres quiméricos, como el centauro, o las sirenas. No es posible seguirlo en la letra menuda de su análisis. Bastará indicar que el procedimiento de Morris consiste en ir dando gradualmente ciertos detalles que van logrando la suspensión de la duda y permiten la aceptación (en el plano del artificio) de lo inverosímil. Es en la gradación de efectos que reside el procedimiento.

Más importante es el segundo ejemplo que maneja Borges. El texto de Poe contiene, según él, dos argumentos:

uno inmediato, de vicisitudes maritimas; otro, infalible, sigiloso y creciente, que sólo se revela al final. (p. 115)

El primero corresponde, aunque Borges no lo dice, a la tradición de la novela de viajes que tiene como ilustrísimo modelo el Robinson Crusoe, de Daniel DeFoe, uno de los antecedentes obligados del realismo. Pero la narración de Poe es una parodia de esos relatos de viajes, no una imitación como el libro de DeFoe. Borges la presenta con estas palabras:

El secreto argumento de esta novela es el temor y la vilificación de lo blanco. Poe finge unas tribus que habitan en la vecinidad del Círculo Antártico, junto a la patria inagotable de ese color, y que de generaciones atrás han padecido la terrible visitación de los hombres y de las tempestades de la blancura. (p. 114-115)

En un estudio, muy conocido y que ya he glosado en otra parte, Jean Ricardou analiza esta parte del articulo de Borges y señala, entre otras cosas, que hay un error aquí: las tribus no habían sido visitadas antes por hombres de raza blanca. La primera visita es, precisamente, la que narra Arthur Gordon Pym. ${ }^{5} \mathrm{El}$ detalle es significativo ya que el error de Borges proviene precisamente de la perspectiva crítica que ha asumido: como no le interesa el aspecto mimético de la novela de Poe, resbala un poco sobre lo que él llama el argumento "inmediato" para concentrarse en el otro, "infalible, sigiloso y creciente", el "secreto argumento". Para Borges sólo cuenta en la novela de Poe, "el temor y la vilificación de lo blanco". De ahí que vincula esta novela con otra obra maestra de la narrativa norteamericana, Moby Dick, de Melville, en donde también campea el horror a lo blanco, en donde lo blanco se identifica con el Mal. No me interesa ahora el error que

5 Jean Ricardou: “Le caractère singulier de cette eau', en Problèmes du nouveau roman (Paris, Editions du Seuil, 1967), pp. 193-207. Véase también mi artículo: "Borges y la Nouvelle Critique", en Revista Iberoamericana, No. 80 (Pittsburgh, Pa., julio-setiembre 1972), pp. 376-383. 
subraya Ricardou, ni tampoco el análisis estructural a que él somete el texto de Poe. Me interesa sí, que a partir de la elucidación de ese argumento "secreto" de la novela de Poe, así como del examen de los procedimientos por los cuales Morris llega a la verosimilitud en su novela mitológica, Borges alcanza ciertas "verificaciones" generales sobre el arte narrativo.

La primera conclusión a que llega es ésta:

Rectamente se induce de lo anterior que el problema central de la novelística es la causalidad. Una de las variedades del género, la morosa novela de caracteres, finge o dispone una concatenación de motivos que se proponen no diferir de los del mundo real. Su caso, sin embargo, no es el común. En la novela tumultuosa y en marcha, esa motivación es improcedente, y lo mismo en los relatos de breves páginas y en la infinita novela espectacular que compone Hollywood con los plateados idola de Joan Crawford y que las ciudades releen. Un orden muy diverso los rige, lúcido y ancestral. La primitiva claridad de la magia. (p. 117)

Aquí está el punto focal de su "poética" narrativa. Al examinar la causalidad de la ficción, Borges distingue dos formas básicas que corresponden a las dos formas de la causalidad en el mundo real. Su análisis es ontológico, y traslada desde el mundo de los objetos al mundo de la escritura la misma visión filosófica. De esta manera, separa drásticamente dos zonas dentro del campo de la narrativa: (a) la que imita la causalidad del mundo real, tal como la presenta la ciencia; (b) la que sigue la causalidad de la magia. Es interesante advertir, desde el comienzo que Borges utiliza para definir la causalidad de la magia, adjetivos como "lúcido", "ancestral" y "primitivo". La asociación de términos es, a primera vista, inesperada. Generalmente se reserva la expresión "lúcido" para los productos más sofisticados de la cultura intelectual: para la ciencia, para la lógica, para la especulación filosófica más rigurosa. Borges, en cambio, lo aplica perversamente a la magia que define, por lo que parece un oximoron, por medio de la expresión: "primitiva claridad"'.

Para fortalecer su enfoque, Borges dedica un par de páginas a una rápida excursión por el campo de la antropología. Aunque es evidente que su fuente principal es el artículo "Magic", de la oncena edición de la Encyclopaedia Britannica, ${ }^{6}$ también es evidente que Borges se ha valido de otras fuentes. Al resumir a Frazer, que postula la ley de la simpatía para la magia:

un vínculo inevitable entre cosas distantes, ya porque su figura es igual-magia imitativa, homeopática,-ya por el hecho de una cercanía anterior-magia contagiosa- (pp. 117-118)

Borges se vale de la Britannica, pero al ofrecer ejemplos de magia, utiliza algunos que no vienen de este artículo. Lo importante, sin embargo, es la conclusión a la que llega Borges:

la magia es la coronación o pesadilla de lo causal, no su contradicción. El milagro no es menos forastero en ese universo que en el de los astrónomos. Todas las leyes naturales lo rigen, y otras imaginarias. Para el supersticioso, hay una necesaria

6 The Encyclopaedia Britannica (New York, The Encyclopaedia Britannica Company, 1911, vol. XVII), pp. 304-310. 
conexión no sólo entre un balazo y un muerto, sino entre un muerto y una maltratada efigie de cera o la rotura profética de un espejo o la sal que se vuelca o trece comensales terribles. (p. 119)

No es mi propósito ahora averiguar si la interpretación que da Borges de la magia es antropológicamente correcta o no. Me interesa subrayar la importancia que tiene para definir su "poética". Contra todos los que creen que el término mágico es sinónimo de misterioso o de maravilloso (es decir: de algo vago, indefinible, o, como se decía en tiempos de Rubén: "inefable"), Borges muy explícitamente afirma que la magia es "la coronación o pesadilla de lo causal"'. También afirma que "todas las leyes naturales, y otras imaginarias"' rigen el universo de la magia. La arbitrariedad, el desorden, el caos son ajenos a ella, no así a la mera realidad.

De inmediato pasa Borges a considerar la aplicación de este principio de causalidad mágica a la novela.

Esa peligrosa armonía, esa frenética y precisa causalidad, manda en la novela también. Los historiadores sarracenos (...) no escriben de sus reyes y jalifas que fallecieron, sino Fue conducido a las recompensas y premios o Pasó a la misericordia del Poderoso o Esperó el destino tantos años, tantas lunas y tantos dias. Ese recelo de que un hecho temible pueda ser atraído por su mención, es impertinente o inútil en el asiático desorden del mundo real, no así en una novela, que debe ser un juego preciso de vigilancias, ecos y afinidades. Todo episodio en un cuidadoso relato, es de proyección ulterior. (pp. 119-120)

Los ejemplos que a continuación cita Borges (tres cuentos de Chesterton; el comienzo del Fausto, de Estanislao del Campo; tres films de Josef von Sternberg) son muy divertidos pero no podemos examinarlos aquí. Bastará mirar la última frase de este párrafo; alli Borges agrega otro ejemplo:

la ilustración más cabal de un orbe autónomo de corroboraciones, de presagios, de monumentos, es el predestinado Ulises de Joyce. Basta el examen del libro expositivo de Gilbert o, en su defecto, de la vertiginosa novela. (p. 121)

Con esa última burla a la erudición, Borges puede preparar la conclusión de su artículo:

Procuro resumir lo anterior. He distinguido dos procesos causales: el natural, que es el resultado incesante de incontrolables e infinitas operaciones; el mágico, donde profetizan los pormenores, lúcido y limitado. En la novela, pienso que la única posible honradez está con el segundo. Quede el primero para la simulación psicológica. (pp. 121-122)

El aparente viraje hacia la ética que realiza Borges en las dos últimas frases del párrafo ("honradez", "simulación") es sólo un artificio: lo que él quiere subrayar es precisamente el valor "poético" de estas expresiones. Dado el desorden del mundo real, el mundo de la ficción sólo puede tomar dos partidos: o imitarlo y caer en la simulación (es decir: en la mimesis), o crear su propio orden, como lo hace la magia. El artículo termina, pues, postulando la analogía de dos procesos causales: el de la magia, el de la narrativa. Al hacerlo, Borges explícitamente denuncia la simulación poética de la novela psicológica y, en forma implícita, denuncia también la simulación de la novela realista. Una narrativa 
mágica queda fundamentada aquí, pero una narrativa en que el término mágico poco o nada tiene que ver con el uso que, desde Franz Roh y Massimo Bontempelli, hasta Arturo Uslar Pietri, Alejo Carpentier y Miguel Angel Asturias (para no hablar de los profesores Flores y Leal), se le viene dando en la crítica contemporánea.

El otro texto de Borges que hay que examinar antes de escribir seriamente sobre el tema es bastante más conocido. Me refiero al prólogo a La invención de Morel, novela de Adolfo Bioy Casares, que su publicó por primera vez en Buenos Aires, en 1940. ${ }^{7}$ Este libro antecede en un año la publicación de $E l$ jardin de senderos que se bifurcan, primera colección de cuentos explícitamente fantásticos de Borges, y es del mismo año que la Antología de la literatura fantástica, que Borges compiló con Bioy y con Silvina Ocampo, y que lleva un prólogo (muy caótico e idiosincrático) de Bioy. La importancia del prólogo de Borges a La invención de Morel no puede encarecerse bastante. Publicado en el momento en que esa novela, la colección de sus cuentos y la Antología habrían de saturar la literatura argentina con una nueva forma de ficción-o mejor dicho: con una nueva forma de presentar la más vieja ficción conocida-, el prólogo adquiere carácter de manifiesto. Lamentablemente, Borges olvidó recogerlo en la colección de sus ensayos críticos que publicó Sur en 1952. Por no estar incluído allí, los críticos que sólo leen libros de Borges, lo han soslayado. ${ }^{8}$ No es exagerado decir que ese prólogo es tan importante para la nueva novela latinoamericana como el prefacio de Cromwell, de Victor Hugo, lo fue para el drama romántico. Aunque tiene la ventaja de ser infinitamente más breve.

Ostensiblemente, el prólogo tiene dos propósitos: el más obvio es presentar la novela de Bioy a la consideración del lector; el más importante, dar los fundamentos de una teoría de la narración que se propone diferir explícitamente de la presentada por Ortega y Gasset en su conocido ensayo de 1925, La deshumanización del arte. Borges habrá de empezar por esta segunda faena. El camino que toma es bastante directo. Después de una cita de Stevenson que, hacia 1882, observó irónicamente que los “lectores británicos desdeñaban un poco las peripecias y opinaban que era muy hábil redactar una novela sin argumento, o de argumento infinitesimal, atrofiado', Borges indica la coincidencia del juicio de Ortega con éste del público inglés:

José Ortega y Gasset (...) trata de razonar el desdén anotado por Stevenson y estatuye en la página 96, que "es muy difícil que hoy quepa inventar una aventura capaz de interesar a nuestra sensibilidad superior', y en la página 97, que esa invención "es prácticamente imposible". En otras páginas, en casi todas las otras páginas, aboga por la novela 'psicológica' y opina que el placer de las aventuras es inexistente o pueril. (p. 9)

Cualquier lector asiduo de Borges reconocerá en algunos rasgos estilísticos (la elección

7 Jorge Luis Borges: "Prólogo", en La invención de Morel, por Adolfo Bioy Casares (Buenos Aires, Losada, 1940), pp. 9-13. En el artículo citado en nota 2, también me ocupo brevemente de este prólogo.

8 Ahora está recogido en un libro de Borges: Prólogos (Buenos Aires, Torres Aguiero Editor, 1975), pp. $22-24$. 
del verbo cuando afirma que Ortega "estatuye", la repetición de "en otras páginas, en casi todas las otras páginas") que el autor argentino está decidido no sólo a discrepar de Ortega sino a tomarle el pelo. La cita, hábilmente incrustada, del párrafo que incluye esta gaffe: "nuestra sensibilidad superior', así lo corrobora. No es extraño, pues, que Borges concluya este pasaje señalando que

Algunos escritores (entre los que me place contar a Adolfo Bioy Casares) creen razonable disentir. (p. 9)

El disentimiento con Ortega ocupa el resto del prólogo. Primeramente, Borges habrá de atacar la novela psicológica con argumentos que ya habían sido esbozados en el artículo, "El arte narrativo y la magia'". De ahí que empiece su análisis, afirmando:

El primero (cuyo aire de paradoja no quiero destacar ni atenuar) es el intrínseco rigor de la novela de peripecias. La novela característica, " psicológica”, propende a ser informe. Los rusos y los discípulos de los rusos han demostrado hasta el hastío que nadie es imposible: suicidas por felicidad, asesinos por benevolencia, personas que se adoran hasta el punto de separarse para siempre, delatores por fervor o por humildad... Esa libertad plena acaba por equivaler al pleno desorden. Por otra parte, la novela " psicológica" quiere ser también novela "realista"' prefiere que olvidemos su carácter de artificio verbal y hace de toda vana precisión (o de toda lánguida vaguedad) un nuevo toque verosímil. Hay páginas, hay capítulos de Marcel Proust que son inaceptables como invenciones: a los que, sin embargo, nos resignamos como a lo insípido y ocioso de cada día. (p. 10)

Por el contrario, frente al desorden de la novela psicológica, frente a su falta de forma, de rigor, Borges presenta el orden, la forma, el rigor, de la novela de aventuras:

La novela de aventuras, en cambio, no se propone como una transcripción de la realidad: es un objeto artificial que no sufre ninguna parte injustificada. El temor de incurrir en la mera variedad sucesiva del Asno de Oro, de los siete viajes de Simbad o del Quijote, le impone un riguroso argumento. (p. 10)

Se reconoce aquí, en un plano más general y con un muestrario de ejemplos más llamativos, el mismo mecanismo que ya estaba funcionando en "El arte narrativo y la magia". Es precisamente la causalidad mágica la que distingue la novela psicológica y realista de la novela tal como la concibe Borges y la practica Bioy. En la segunda etapa de su análisis, Borges pasa del examen intelectual del problema al empírico:

Todos tristemente murmuran que nuestro siglo no es capaz de tejer tramas interesantes; nadie se atreve a comprobar que si alguna primacia tiene este siglo sobre los anteriores, esa primacía es la de las tramas. Stevenson es más apasionado, más diverso, más lúcido, quizá más digno de nuestra amistad que Chesterton; pero los argumentos que gobierna son inferiores. De Quincey, en noches de minucioso terror, se hundió en el corazón de laberintos hechos de laberintos, pero no amonedó su impresión de unutterable and self-repeating infinities en fábulas comparables a las de Kafka. Anotó con justicia Ortega y Gasset que la 'psicologia' de Balzac no nos satisface; lo mismo cabe anotar de sus argumentos. (...) Me creo libre de toda superstición de modernidad, de cualquier ilusión de que ayer difiere intimamente de hoy o diferirá de mañana; pero considero que ninguna otra época 


\section{ESTUDIOS}

posee novelas de tan admirable argumento como The Invisible Man, como The Turn of the Screw, como Der Prozess, como Le Voyageur sur la terre, como ésta que ha logrado, en Buenos Aires, Adolfo Bioy Casares. (p. 11)

El resto del prólogo está dedicado a examinar la novela de Bioy. Dejando de lado lo que se refiere estrictamente a esta novela, indicaré un par de lugares que tienen que ver con esa "poética" de la narración mágica, o fantástica, que aparece aquí esbozada. Uno de los puntos principales del análisis de Borges es la comparación de la obra de Bioy con las novelas policiales:

Las ticciones de indole policial-otro género típico de este siglo que no puede inventar argumentos-refieren hechos misteriosos que luego justifica e ilustra un hecho razonable; Adolfo Bioy Casares, en estas páginas, resuelve con felicidad un problema acaso más difícil. Despliega una Odisea de prodigios que no parece admitir otra clave que la alucinación o que el símbolo, y plenamente los descifra mediante un solo postulado fantástico pero no sobrenatural. (p. 12) ${ }^{9}$

Antes de pasar a otro tema quisiera subrayar el paréntesis en que Borges destaca el género policial como otro género actual que desmiente la tesis de Ortega sobre la incapacidad de nuestro siglo de "tejer tramas interesantes". Este es su last parting shot contra Ortega. El resto es un elogio de La invención de Morel. No podemos examinar aquí la relación de la "poética" que esboza Borges con el texto mismo de la novela de Bioy. Por otra parte, el profesor Alfred MacAdam se ocupa de esto en la ponencia que ha presentado al mencionado Congreso de East Lansing. (Véase la Memoria del XVI Congreso del Instituto Internacional de Literatura Iberoamericana, 1975, pp. 300-313). Lo que quiero subrayar antes de pasar adelante es que con este prólogo Borges reafirma su rechazo de la simulación psicológica y realista, y confirma su interés en la narración mágica o fantástica. Los cuentos que él habría de publicar a lo largo de los años cuarenta-recogidos en tres volúmenes sucesivos: El jardin de senderos que se bifurcan (1941), Ficciones (1944, que incorpora todos los cuentos de El jardin, y agrega otros), El Aleph (1949)-, demostrarian en la práctica esa " "poética". También numerosos ensayos (que luego compilará en Otras inquisiciones, 1952) habrian de ofrecer capitulos dispersos de esa " poética". Es imposible examinar aquí en detalle todo ese vasto corpus. Me limitaré a estudiar un trabajo muy significativo pero que por su naturaleza oral y por la circunstancia en que fue comunicado no se conoce todavía lo suficiente. Me refiero a la conferencia titulada "La literatura

9 En un reciente trabajo de Ana María Barrenechea - "Ensayo de una tipología de la literatura fantástica. (A propósito de la literatura hispanoamericana)', en Revista Iberoamericana, No. 80 (Pittsburgh, Pa., JulioSetiembre 1972), pp. 391-403-hay un intento de aplicar a Borges algunas teorias de Tzvetan Todorov en el conocido libro, Introduction à la littérature fantastique (Paris: Editions du Seuil, 1970). Lamentablemente Barrenechea no ha tenido en cuenta este texto de Borges que le hubiera servido para demostrar mejor algunas de las confusiones y errores en que incurre Todorov. La crítica más completa y demoledora que conozco de las "teorías" de este notorio divulgador se encuentra en Le récit fantastique. La poétique de l'incertain, de Iréne Bessière (Paris: Larousse, 1974). Dicho libro no sólo demuestra la insuficiencia del análisis de Todorov sino que sitúa muy adecuadamente la obra de Borges en el contexto general del relato fantástico. Al situar el género dentro de la poética de lo incierto y no apoyarse exclusivamente en la vacilación del lector o del protagonista del relato (elemento secundario si los hay), Bessière evita caer en el error más grueso de Todorov. Aunque su libro demuestra que Bessière no conoce al detalle la bibliografía crítica sobre Borges, y que se apoya mucho en el Borgès par lui même, publicado por las Editions du Seuil en 1970, en Paris, su sistematización del problema de la literatura fantástica es muy superior al de Todorov, y a los intentos algo caóticos de Barrenechea. 
fantástica" que dió Borges en Montevideo, el 2 de setiembre de 1949, en Amigos del Arte.

No ha quedado otro registro de esa conferencia que un resumen publicado en un periódico montevideano por Carlos Alberto Passos. Ayudado por una memoria increíble y por copiosas notas tomadas sin ayuda de la taquigrafía, Passos solía reconstruír las conferencias casi verbatim. Por eso, el día 3 de setiembre aparecía en El País, un valioso resumen de la de Borges. ${ }^{10}$ Por otra parte, mucho de lo que habia dicho Borges era material que él había ya presentado en dos artículos de La Nación, de Buenos Aires: "La flor de Coleridge" (setiembre 23, 1945), y "Magias parciales del Quijote"' (noviembre 6, 1949). (A mbos artículos están ahora en Otras inquisiciones.) ${ }^{11}$ Con ese material, y mis propios recuerdos de la conferencia, más el análisis de su propia obra de ficción, compuse el mismo año de 1949 un artículo que publiqué en la revista Número, de Montevideo, que entonces dirigía: "Jorge Luis Borges y la literatura fantástica". Allí se examina la teoría y la práctica de la narración fantástica en Borges. Me apoyaré en él, y en los otros textos invocados, para indicar los fundamentos de esa "poética" de la narración que Borges estaba desarrollando entonces.

Lo primero que Borges ataca en su conferencia es la noción popular (errónea por anacrónica) de que "la literatura fantástica es una especie de capricho contemporáneo" y que "la verdadera literatura es aquella que elabora novelas realistas, y que ofrece una verosimilitud casi estadistica"'. Lo contrario es históricamente cierto:

Las novelas realistas empezaron a elaborarse a principios del siglo XIX, en tanto que todas las literaturas empezaron con relatos fantásticos. Lo primero que encontramos en la historia de las literaturas son narraciones fantásticas. (...) Por otra parte, la idea de (que) la literatura coincida con la realidad es una idea que se ha abierto camino de un modo muy lento: así, los actores que, en tiempos de Shakespeare o de Racine, representaban las obras de éstos, no se preocupaban, v.gr., del traje que debían vestir en la escena, no tenian esa especie de escrúpulo arqueológico sustentado por la literatura realista. La idea de una literatura que coincida con la realidad es, pues, bastante nueva y puede desaparecer; en cambio, la idea de contar hechos fantásticos es muy antigua, y constituye algo que ha de sobrevivir por muchos siglos. (p. 4)

A continuación, Borges examina los procedimientos de la literatura fantástica que, según él, "pueden reducirse, ciertamente, a unos pocos": (a) La obra de arte dentro de la misma obra; (b) la contaminación de la realidad por el sueño; (c) el viaje en el tiempo; (d) el doble. En otros textos impresos, Borges ha hablado de otros procedimientos, o ha calificado estos mismòs de otra manera. No podemos seguirlo aquí en el detalle de su

10 'Conferencias. Sobre 'La literatura fantástica' disertó ayer Jorge Luis Borges', en El Pats (Montevideo, setiembre 3, 1949), p. 4.

11 Jorge Luis Borges: Otras inquisiciones (Buenos Aires, Sur, 1952). "La flor de Coleridge"' está en las pp. 17-20; "Magias parciales del Quijote", en las pp. 55-58. 
análisis. Nos limitaremos pues a considerar con más espacio los cuatro arriba indicados.

El procedimiento de la obra dentro de la obra está ya en el Quijote: en la segunda parte, los personajes han leido el primer volumen, de 1605, y lo discuten; está también en Hamlet: los cómicos representan ante la Corte una tragedia que tiene gran semejanza con la de Hamlet. Pero es posible rastrearlo antes del Barroco. En la Eneida (libro I), el héroe troyano contempla en Cartago unas pinturas murales en que se muestra la destrucción de Troya, de la que él acaba de escapar, y se reconoce "mezclado entre los príncipes aqueos". Ya antes, en la Ilíada, modelo de Virgilio, Helena borda en el canto III un doble manto de púrpura cuyo tema es el mismo del poema; el combate de troyanos y aqueos por la posesión de Helena. En estos ejemplos (y en otros que Borges propone, o pueden proponerse complementariamente) se advierte que la misma obra literaria postula la realidad de su ficción al introducirse como realidad en el mundo que sus personajes habitan.

El procedimiento de introducir imágenes del sueño que alteran la realidad ha sido explotado por el folklore de todos los pueblos; también, magistralmente por Coleridge, en una nota que el propio Borges cita y traduce así:

Si un hombre atravesara el Paraíso en un suefio, y le dieran una flor como prueba de que había estado ahí, y si al despertar encontrara esa flor en su mano... entonces, qué? (Otras Inquisiciones, pp. 17-18)

La flor de Coleridge, combinada con otro recurso-el viaje en el Tiempo-ha engendrado otras ficciones famosas que el mismo Borges apunta. Así, por ejemplo, en The Time Machine, de H. G. Wells, el protagonista viaja hacia el porvenir y trae una flor marchita. Borges comenta:

Más increíble que una flor celestial o que la flor de un sueño, es la flor futura, la contradictoria flor cuyos átomos ahora ocupan otros lugares y no se combinaron aún. (id., 18-19)

Henry James, que conocía el texto de Wells, propone una versión más fantástica en The Sense of the Past, novela que no llegó a concluír pero cuyo argumento total es conocido: un retrato que data del siglo XVIII representa misteriosamente al protagonista, que fascinado por la tela logra trasladarse a la fecha en que fue pintada y consigue que el pintor, tomándolo de modelo, comience la obra:

James! crea|sí un incomparable "regressus in infinitum", ya que su héroe, Ralph Pendrel, se traslada al siglo XVIII porque lo fascina un viejo retrato, pero ese retrato requiere, para existir, que Pendrel se haya trasladado al siglo XVIII. La causa es posterior al efecto, el motivo del viaje es una de las consecuencias del viaje. (id., 19)

Funciona aquí, como se ve, esa "causalidad mágica"' de la que hablaba Borges en "El arte narrativo y la magia", aunque en su ensayo sobre "La flor de Coleridge", Borges no establezca el vínculo. Con respecto al último procedimiento, el de los dobles, también éste abunda en antecedentes ilustres. En su conferencia recuerda dos: uno de los cuentos de Edgar Poe que se titula "William Wilson"'; una narración de Henry James, "The Jolly Corner", que presenta la sugestiva variante de referirse a un doble que habita no otro tiempo real sino un tiempo posible, que es un fantasma, en fin. En su conferencia, también 
explora Borges otro aspecto del tema: la supuesta gratuidad, la aparente evasión, de la literatura fantástica. Para él, sin embargo, la literatura fantástica se vale de ficciones no para evadirse de la realidad sino para expresar una visión más honda y compleja de la realidad. Toda esa literatura está destinada más a ofrecer metáforas de la realidad-por las que el escritor quiere, trascender las observaciones superficiales o pedestres del realismo-que evadirse a un territorio gratuito. De ahí que no cualquier ficción irresponsable pueda valer; de ahí que la literatura fantástica requiera más lucidez y rigor, más auténtica exigencia de estilo que la mera copia de la realidad cotidiana, que ésta sí puede abundar en incoherencias, en arbitrariedades, en el tedio-como el artículo sobre "El arte narrativo y la magia", o el prólogo a La invención de Morel, ya han demostrado largamente.

El mismo Borges acerca en su conferencia de 1949 dos ejemplos de esta dimensión trascendente de la literatura fantástica: The Invisible Man, de H. G. Wells, y Der Prozess, de Franz Kafka. Ambas obras plantean el mismo tema: la soledad del hombre, su incomunicabilidad última, pero utilizan distintos procedimientos narrativos: una es una fantasía científica, contada en términos de minucioso realismo; la otra, es una pesadilla expresionista que conserva su irrealidad, su angustia, sus leyes arbitrarias, a pesar de estar expuesta con detalles de la más penosa o trivial materialidad. Citaré un pasaje de su conferencia en que se refiere a este tema, y dice de The Invisible Man:

¿Por qué Wells ha contado esa historia? Porque ese hombre perseguido y solo, de su novela, viene a ser una especie de símbolo de la soledad. Y lo mismo ocurre con los demás temas de la literatura fantástica, porque son como verdaderos símbolos de estados emocionales de procesos que se operan en todos los hombres. Por eso, no es menos importante la literatura fantástica que la realista. (p. 4)

De esta manera destruye Borges la falacia que supone que la literatura fantástica es "deshumanizada"' (como diría Ortega, y repite el profesor Flores) o "escapista"' (como parece creer el profesor Leal). Pero Borges va un poco más lejos. Después de afirmar la importancia de la literatura fantástica frente a la realista, agrega:

Ante dos ejemplos como Crimen y castigo, de Dostoievski, y la Historia de Macbeth, v. gr., es de creer-afirmó Borges-, que ninguna persona pueda pensar que una obra es menos real y menos terrible que la otra; porque simplemente se trata de convenciones literarias distintas. (p. 4)

O dicho de otro modo: la literatura realista es tan "convencional", tan "artificial", tan "ficticia", como la fantástica. Naturalmente que estas afirmaciones hoy no parecerán paradójicas o extrañas a nadie. Pero no hay que olvidar que estos textos de Borges que ahora invoco deben ser situados en el contexto de los años treinta y cuarenta y aún cincuenta en que en Buenos Aires se creía que Eduardo Mallea era un gran escritor, en que toda la izquierda proclamaba unánime el "realismo socialista" (que debe ser llamado rectamente cosmético estalinista) y en que los existencialistas a la francesa alimentaban el bostezado si que interminable debate sobre la littérature engagée. En ese contexto, las palabras de Borges resonaban en el desierto.

Lo malo no es eso: sino que tampoco eran escuchadas por quienes pretendian invocar los textos de Borges para sustentar una teoría del Realismo Mágico que nada tenía que ver 
con esos textos y que (en el mejor de los casos) era sólo lateral a lo que Borges estaba haciendo en la práctica de sus ficciones y en la "poética"' de sus ensayos. En el peor de los casos, como se ha visto por el artículo del profesor Flores, la aproximación conducía a un travestimiento total de la obra de Borges.

Sólo cuando los ensayos de Otras inquisiciones y el prólogo a La invención de Morel empezaran a ser leídos en Francia (por gente como Maurice Blanchot y Alain RobbeGrillet, Gérard Genette y Jean Ricardou, Michel Foucault y Philippe Sollers), la critica latinoamericana habría de advertir qué sentido tenía esa "poética" y hacia dónde apuntaba. Esa es otra historia, es claro, y la he contado en otra parte. ${ }^{12}$ Aquí sólo quiero reiterar que con muy contadas excepciones (que no detallaré pero son conocidas) la crítica latinoamericana de Borges debió esperar a la lectura de los escritores franceses para entender lo que su obra entera venía diciendo por lo menos desde 1932.

Lo que venía diciendo cabe en una fórmula muy simple: todo es ficción y entre la simulación psicológica o realista es preferible el rigor, la lucidez, la causalidad mágica de la literatura fantástica. 
